\title{
CONCEPTUAL FRAMEWORK FOR EFFICIENT 802.11 A/B/G/N WIRELESS NETWORKS INFRASTRUCTURE TO IMPROVE CAMPUS INTERNET CONNECTIVITY
}

\author{
Owusu Nyarko-Boateng ${ }^{*}{ }^{\square}$, Isaac Kofi Nti ${ }^{2}$, Adebayo Felix Adekoya ${ }^{1}$, Benjamin \\ Asubam Weyori ${ }^{1}$, Stephen Appiah ${ }^{1}$ \\ ${ }^{* 1}$ Department of Computer Science and Informatics, University of Energy and Natural Resources, \\ Ghana \\ 2 Department of Computer Science, Sunyani Technical University, Ghana
}

DOI: https://doi.org/10.29121/ijetmr.v7.i11.2020.802

Article Citation: Owusu NyarkoBoateng, Isaac Kofi Nti, Adebayo Felix Adekoya, Benjamin Asubam Weyori, and Stephen Appiah. (2020). CONCEPTUAL FRAMEWORK FOR EFFICIENT 802.11 A/B/G/N WIRELESS NETWORKS INFRASTRUCTURE TO IMPROVE CAMPUS INTERNET CONNECTIVITY. International Journal of Engineering Technologies and Management Research, 7(11), 1-8. https://doi.org/10.29121/ijetmr.v7 i11.2020.802

Published Date: 09 November 2020

Keywords:

Quality of Service

Wireless Network

Availability

Accessibility

High-Speed Internet

IEEE802.11

\section{ABSTRACT}

Provision of internet service on university campuses has become essential and critical drivers to the progress and success of contemporary universities. Despite this intriguing technological advancement, universities are finding it challenging to provide the required quality of internet services to meet the high expectation of users on campus. Proper infrastructure, inadequate bandwidth, and effectiveness of internet service delivery achieve an optimal balance between available internet resources and the demands placed on internet resources. This paper set out to find out the state of internet infrastructures in the selected universities in Sunyani metropolis in Ghana. This paper conducted three significant investigations. A survey on user perception was conducted to ascertain the quality of user experience. A physical examination was also conducted. A wireless network analytical tool was deployed to examine the quality of 802.11 $\mathrm{a} / \mathrm{b} / \mathrm{g} / \mathrm{h}$ wireless signal on the campuses of the selected university campuses. The results of the three investigations revealed a poor wireless network at the university campuses. The paper proposed a conceptual framework to improve the network infrastructure on university campuses.

Motivation/Background: This study was motivated by the number of studies in literature concerning the access, usage, and quality of internet service in Africa. The study was designed to examine the quality internet service and the quality of experience (QoE) of internet user in three universities in the Sunyani metropolis in relation to access, availability and quality of internet.

Method: An inSSIDer wireless signal analytics tool was used to examine the quality of signal strength on the selected University campuses. The tool has the ability to measure certain essential indicators used to determine the quality of signal strength, bandwidth, frequency and can report whether the signal is secure or insecure. The test was carried at several locations on the campuses at different times. The result of the test and simulation by the inSSIDer tool, the signal strength at the campuses indicated a weaker signal in all three campuses.

Results: The results obtained from the test conducted at the three University campuses revealed that the wireless signals propagated at the university campuses were very poor.

Conclusions: A conceptual framework has been designed to help reduce the signal attenuations significantly. 


\section{INTRODUCTION}

Internet connectivity in Africa has been characterized by several technical challenges, coupled with the high cost of accessing and using the service. Many people, including university students and workers, leverage on internet service to perform several activities [1]. From individual users to the high-level deployment in the organization, the internet has gained a firm ground in trading and commerce, education, healthcare, transport services and other important areas which require internet to enhance their operations.

Universalities usually provides free internet service for staff and student on campus [2]. This phenomenon has improved research, teaching and learning on the university campuses. Universities spend significant amounts of money on providing high-speed internet connectivity on campus [1], [2]. However, in most cases, users usually have issues with the availability of the internet service and at the instance where service is available, accessibility challenge [3], [4], [5] set in. this prompted the researchers to investigate the cause of poor internet service on campus. Several tests were conducted on the campuses of three selected universities in Ghana. A conceptual framework was proposed to improve the quality of internet service on campus because QoS can be achieved when the internet service the universities ensure quality delivery of service through a robust and high capacity infrastructure which deliver high-speed internet service to the end [6], [7].

\section{IEEE 802.11 WIRELESS INFRASTRUCTURE}

The 802.11 standard is a wireless technology which establishes and defines the mode of channelling the unlicensed radio frequency bands in wireless local area networks (WLANs). IEEE 802.11 Wireless Infrastructure is deployed in connecting communications devices with wireless network adapters to an existing wired network with the help from wireless router or wireless access point (WAP). Several modes of IEEE 802.11 wireless infrastructures such as 802.11a, 802.11b, 802.11g, and 802.11n have been implemented in the WLAN [3]. The 802.11 devices operating in the $5 \mathrm{GHz}$ band is less likely to experience interference than devices that operate in the $2.4 \mathrm{GHz}$ band because there are fewer consumer devices that use the $5 \mathrm{GHz}$ band. Also, higher frequencies allow for the use of smaller antennas. Generally, most 802.11 uses multiple radios and antennae at endpoints, each broadcasting on the same frequency to establish multiple streams [4], [5]. The multiple input/multiple output technologies split a high data-rate stream into multiple lower rate streams and broadcasts.

\subsection{CAMPUS INTERNET CONNECTIVITY}

Today internet users in the universities expect nothing less than sustained, reliable high-speed internet connectivity that does not fail, even for a second. Failure in campus internet service is as a result of insufficient network infrastructure [7], signal obstructions, and low bandwidth. In growing institutions where the number of staff and students outnumbers the network infrastructure on campus, accessibility to the facility will be a challenge to many. If the transmission infrastructures are not well-positioned to where users are mostly clustered like classrooms, library, cafeteria, and so on; then the availability of internet service to users could be limited which may lead to severe congestion and a challenge in internet accessibility [8], [9], [10]. Trees, tall building and other high objects on campus could obstruct the availability of internet service when communication signal scatters, diffract or reflect after hitting the obstructions. Low bandwidth is another cause of poor campus internet service, which affects user experience. Large user population on campus require large high-speed internet service [6], [8], [11].

\section{RELATED WORKS}

Previous work on-campus internet service [3] has been conducted in various forms regarding the quality and experience of internet service. Others did similar work on accessibility and usability of internet service at the various university campuses [6], [7]. Various methods were used to achieve the desired results of their work to ensure uniqueness and scientific novelty. For instance, [4], [5] investigated the level of wireless network awareness, and the problems faced by the students on the campus and their level of competence. [7], [8] confirmed in their work that the IEEE 802.11 protocol operates in the unlicensed spectrum and experiences unregulated interference, making it 
difficult to guarantee the quality of service (QoS). The campus network is used for several tasks such as teaching, research, management and communication with others outside the school. However, a study was conducted on the issue of network security which has become a priority to most educational institutions across the globe [6], [7], [8]. This paper did further work which offers the best solution to overcome the challenges of the campus internet service.

\section{METHODOLOGY}

This study was motivated by the number of studies in literature concerning the access, usage, and quality of internet service in Africa. The study was designed to examine the quality internet service and the quality of experience (QoE) of internet user in three universities in the Sunyani metropolis in relation to access, availability and quality of internet. An explorative study of the quality of experience of the internet of users in the three Ghanaian universities in the Sunyani municipality was conducted. The universities are; Campus_1, Campus_2, and Campus_3. The universities are in the same city but are located far apart from each other geographically.

\section{RESULTS AND DISCUSSION}

The results obtained from the various surveys conducted in the study indicated that users were not happy with the quality of internet service on the campuses. The accessibility and the utilization of the service a major challenge, according to the users of the service.

\subsection{SURVEY OF USERS}

The survey was analyzed to determine the mean opinion score of the respondent's. The MOS of the survey was 3.5 based on the 5-degree Likert scale deployed. The results of the survey informed the researchers to investigate further into the cause of poor 802.11 wireless distribution on the three campuses.

\subsection{SURVEY OF NETWORK INFRASTRUCTURE ON THE CAMPUSES}

The researchers conducted an inspection on the architecture of the campuses wireless network elements. It was observed that the topology and the physical layout of the various wireless network element were contributing factor to the impairment of the wireless signal on the three campuses. Some the causes of this signal impairment are obstructions of the signal by objects such as tree and tall buildings, inappropriate antenna spacing, low signal transmission power, etc. these factors may lead to severe signal interference and Free space loss [7].

\section{INVESTIGATING WIRELESS SIGNAL STRENGTH OF THE THREE CAMPUSES}

An inSSIDer wireless signal analytics tool was used to examine the quality of signal strength on the selected University campuses. The tool has the ability to measure certain essential indicators used to determine the quality of signal strength, bandwidth, frequency and can report whether the signal is secure or insecure. The test was carried at several locations on the campuses at different times. The result of the test and simulation by the inSSIDer tool, the signal strength at the campuses indicated a weaker signal in all three campuses.

\subsection{CAMPUS_1}

The result obtained from Campus 1 has been shown in Figure 1 figure 2. The result indicates poor signal strength for all the available WAP on the campus except Campus Augustus, which was $-49 \mathrm{dBm}$. 

Connectivity

\begin{tabular}{|c|c|c|c|c|c|c|c|}
\hline SSID & SIGNAL & RA... & CLI... & CHANNELS & SECURITY & MODE & MAX R... \\
\hline î̉ 82:2A:A8:A1:D5:17 (hidden) & $-90 \mathrm{dBm}$ & 1 & 0 & 11 & 8 & $b, g, n$ & 130.0 \\
\hline î Angelus II & $-91 \mathrm{dBm}$ & 1 & 7 & 11 & 7 & $b, g, n$ & 130.0 \\
\hline î Campus Augustus & $-49 \mathrm{dBm}$ & 1 & & $7+11$ & 7 & $b, g, n$ & 300.0 \\
\hline in CAMPUS-WIFI-AQUINAS & $-66 \mathrm{dBm}$ & 1 & & 1 & 7 & $b, g, n$ & 130.0 \\
\hline î̀ dd-wrt & $-85 \mathrm{dBm}$ & 1 & & 6 & 0 & $b, g$ & 54.0 \\
\hline î DIRECT-4d-HP M130f Laser]et & $-77 \mathrm{dBm}$ & 1 & & 6 & 8 & $g, n$ & 144.4 \\
\hline ï DIRECT-QNEMERALDmsYG & $-87 \mathrm{dBm}$ & 1 & & 11 & 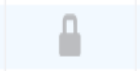 & $g, n$ & 144.4 \\
\hline î̉ Masters & $-74 \mathrm{dBm}$ & 1 & & 6 & 0 & $b, g$ & 54.0 \\
\hline
\end{tabular}

Figure 1: signal strength for Campus_1

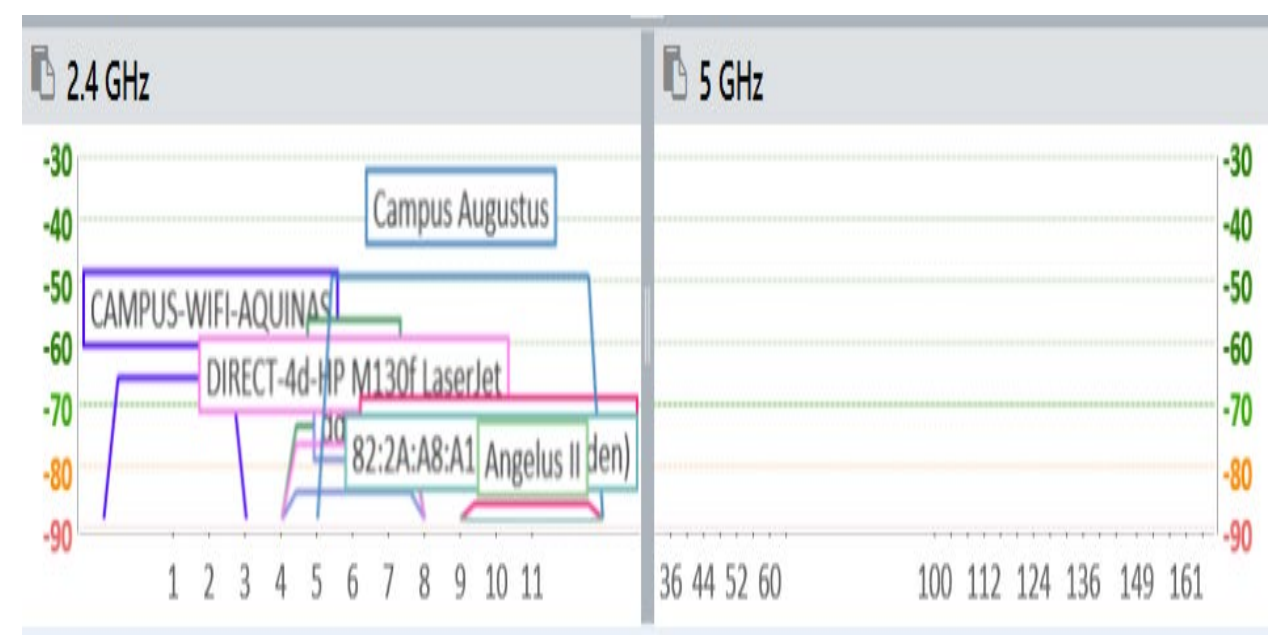

Figure 2: Graphical representation of the signal strength of campus_1

\subsection{CAMPUS_2}

Similarly, the result obtained from Campus_2 has been shown in figure 3and figure 4. The result indicates poor signal strength for all the available WAP on the campus.

\begin{tabular}{|c|c|c|c|c|c|c|c|}
\hline SSID & SIGNAL & RA... & CLl... & CHANNELS & SECURITY & MODE & MAX R... \\
\hline in Directorate of Int'l. Relation & $-84 \mathrm{dBm}$ & 1 & & 6 & 0 & $b, g, n$ & 144.4 \\
\hline in itel it1409 & $-91 \mathrm{dBm}$ & 1 & & 11 & 0 & $b, g, n$ & 72.2 \\
\hline ïi JONESARTHUR-PC 4822 & $-90 \mathrm{dBm}$ & 1 & & 11 & 0 & $g, n$ & 72.2 \\
\hline ï RTR01-Tech-Sunyani & $-89 \mathrm{dBm}$ & 1 & & 7 & 7 & $b, g$ & 54.0 \\
\hline ï SLTF & $-86 \mathrm{dBm}$ & 1 & 3 & $1+5$ & O & $b, g, n$ & 270.0 \\
\hline ï STU_Cloud & $-84 \mathrm{dBm}$ & 1 & & 11 & 7 & $b, g, n$ & 130.0 \\
\hline iin STUAdmin & $-83 \mathrm{dBm}$ & 1 & & 1 & 7 & $b, g$ & 54.0 \\
\hline iin TP-LINK_EEBG & $-84 \mathrm{dBm}$ & 1 & & $2+6$ & 0 & $b, g, n$ & 150.0 \\
\hline
\end{tabular}

Figure 3: signal strength for Campus_2 


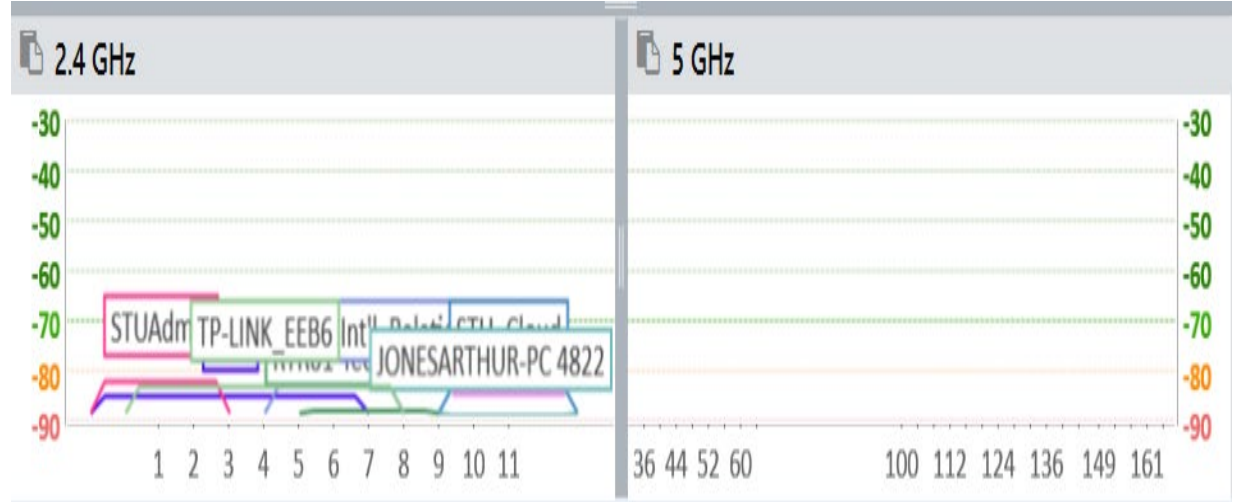

Figure 4: Graphical representation of the signal strength of campus_2

\subsection{CAMPUS_3}

The result obtained from Campus_3 has been shown in figure 5 and figure 6. The result indicates low signal strength for all the available WAP on the campus except ITD WIFI which recorded $-49 \mathrm{dBm}$.

\begin{tabular}{|c|c|c|c|c|c|c|c|}
\hline SSID & SIGNAL & RADIOS & CHANNELS & & SECURITY & MODE & MAX RATE \\
\hline thorks-Wireless of & $-48 \mathrm{dBm}$ & 1 & & 6 & A & $b, g_{1} n$ & 216.7 \\
\hline Connectify-me & $-59 \mathrm{dBm}$ & & & 11 & 月 & $b, g, n$ & 72.2 \\
\hline ITTD Wireless & $.76 \mathrm{dBm}$ & & & 3 & A & $b, g, n$ & 130.0 \\
\hline ITD-WIFI & $-49 \mathrm{dBm}$ & & & 6 & A & $b, g, n$ & 216.7 \\
\hline Saw-Mill-Wireless & $.73 \mathrm{dBm}$ & & & 11 & A & $b, g, n$ & 144.4 \\
\hline Syndicate-Block-Wireless-1 & $.68 \mathrm{dBm}$ & & & 9 & 8 & $b, g, n$ & 144.4 \\
\hline Syndicate-Block-Wireless-2 & $.94 \mathrm{dBm}$ & & & 1 & A & $b, g, n$ & 144.4 \\
\hline UENR-Cafeteria-Wireless & $.69 \mathrm{dBm}$ & & & 6 & 0 & $b, g, n$ & 144.4 \\
\hline
\end{tabular}

Figure 5: signal strength for Campus_2

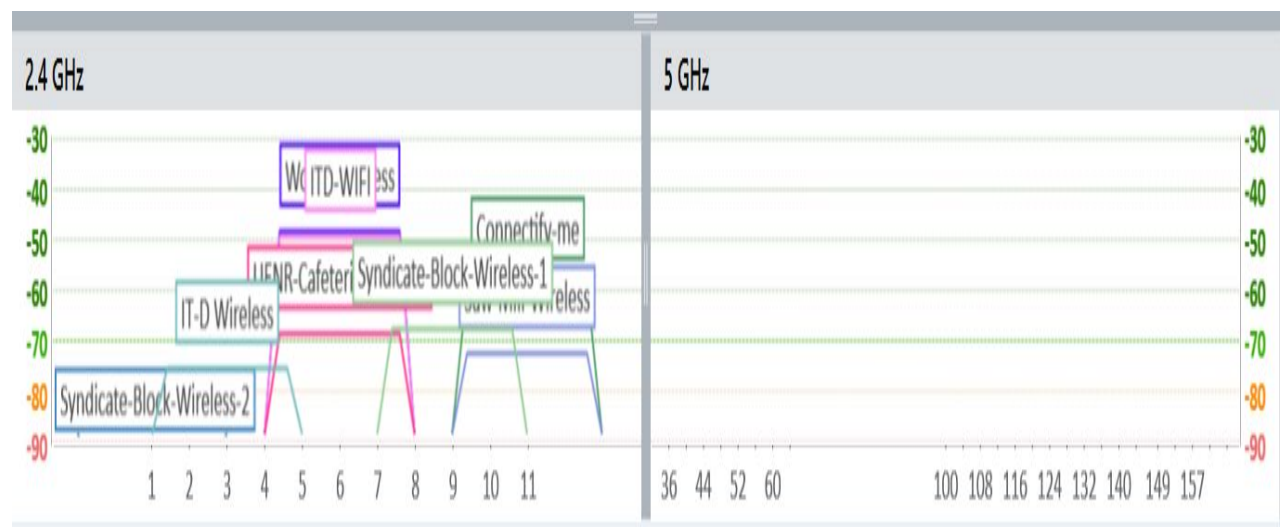

Figure 6: Graphical representation of the signal strength of campus_2

The test results shown in table 1 indicate a severe drop in data transmission speed due to poor signal strength. The research also identified a major vulnerability among four WAP which had its access point opened to the all. This situation is extremely dangerous to a campus wireless network infrastructure. Other parameters were critical in the test were bandwidth, channels, modes, several clients detected on each WAP which represents the utilization. 
Table 1: Results of the signal strength test

\begin{tabular}{|c|c|c|c|c|c|c|c|c|}
\hline AP & Clients & Channel & Bandwidth & Utilization & Signal & Mode & Security & Max. \\
\hline Angelus & 7 & 11 & 20 & $12.8 \%$ & -89 & b,g,n & open & $130 \mathrm{~kb}$ \\
\hline Camp Angelus & 11 & $7+11$ & 40 & $24.3 \%$ & -50 & b,g,n & open & $300 \mathrm{~kb}$ \\
\hline Acquinas & 10 & 1 & 20 & $17 \%$ & -64 & b,g,n & open & 130 \\
\hline Masters & 9 & 6 & 20 & $9 \%$ & -75 & b,g & closed & 54 \\
\hline Direct & 13 & 11 & 20 & $11 \%$ & -85 & g,n & closed & 144.4 \\
\hline (Hidden) & 17 & 11 & 20 & $27.5 \%$ & -90 & b,g,n & closed & 130 \\
\hline Uni_Admin & 9 & 1 & 20 & $22.8 \%$ & -82 & b,g & open & 54 \\
\hline Uni_Cloud & 6 & 11 & 20 & $36 \%$ & -85 & b,g,n & open & 130 \\
\hline Directorate & 2 & 6 & 20 & $6 \%$ & 86 & b,g,n & closed & 144.4 \\
\hline SLTF & 3 & $1+5$ & 40 & $22.7 \%$ & -82 & b,g,n & closed & 270 \\
\hline TP_Link & 17 & $2+6$ & 40 & $29 \%$ & -83 & b,g,n & closed & 150 \\
\hline Works & 12 & 6 & 20 & $18 \%$ & -49 & b,g,n & closed & 216.7 \\
\hline IT_D & 11 & 3 & 20 & $25 \%$ & -73 & b,g,n & closed & 130 \\
\hline Syndicate_1 & 8 & 1 & 20 & $32 \%$ & -62 & b,g,n & closed & 144.4 \\
\hline Syndicate_2 & 7 & 1 & 20 & $17.2 \%$ & -63 & b,g,n & closed & 144.4 \\
\hline Cafeteria & 9 & 6 & 20 & $23 \%$ & -77 & b,g,n & closed & 144.4 \\
\hline Saw_Mill & 19 & 11 & 20 & $13.5 \%$ & -73 & b,g,n & closed & 144.4 \\
\hline IT_ & 15 & 6 & 20 & $11.8 \%$ & -49 & b,g,n & closed & 144.4 \\
\hline
\end{tabular}

\section{PROPOSED FRAMEWORK FOR EFFICIENT CAMPUS WIRELESS NETWORK INFRASTRUCTURE}

Delivery of internet service on university campuses has been an essential and critical driver to the success of modern-day universities. Nowadays, the internet has become an indispensable infrastructure for hosting critical campus-wide enterprise software for facilitating course delivery, enhancing learning, providing support for practical lectures and exercises, classroom management, human resources, financial and general administrative services. Despite this, universities are finding it challenging to provide the required services to meet the high expectation of users.

This paper provides an alternative solution by proposing an architectural design for the campus wireless networks to mitigate the myriads of challenges confronting the users, as indicated in figure 7.

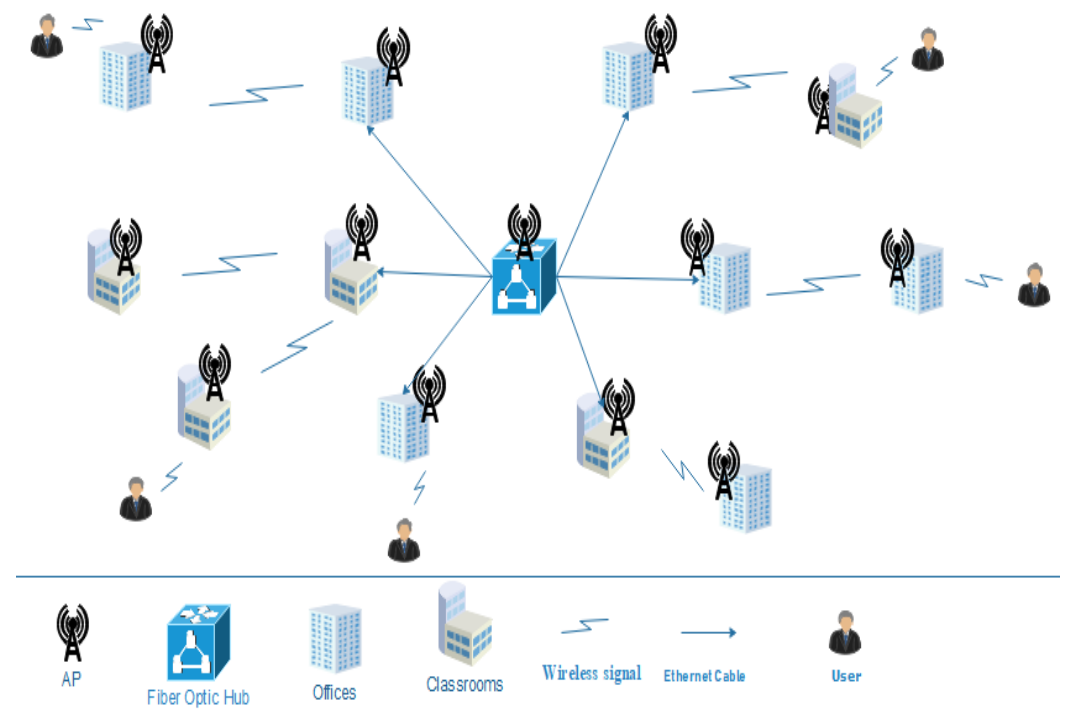

Figure 7: Proposed Framework for efficient Campus Wireless Network 
The proposed architecture has been designed to meet the wireless communication standards in order to avert the numerous challenges associated with the poorly planned campus wireless network. The link between the hub and the next WAP has been designed with a cable length of $100 \mathrm{~m}$. This is to allow for maximum throughput between the two nodes. The communication between WAP devices has also been designed to improve data throughput for users in close proximity to the proposed high gain antenna with $2.4 \mathrm{Ghz}$ frequency $(f)$ for longer transmission distance and $5 \mathrm{Ghz}$ for shorter distance as obtained in figure $10.802 .11 \mathrm{a} / \mathrm{b} / \mathrm{g} / \mathrm{n}$ WAP to WAP signal strength and connections has been improved based on the new infrastructure proposed. This improvement overcomes the existing scheme where all the university campuses had the frequency of their wireless antennae to be $2.4 \mathrm{Ghz}$. The research implemented a free-space path loss (FSPL) technique to improve the point-to-point campus wireless signal.

$$
F S P L=20 \log _{10}(d)+20 \log _{10}(f)+20 \log _{10}\left(\frac{4 \pi}{c}\right)-G_{T_{x}}-G_{T_{x}}
$$

where $d$ is the distance between the antennas, $f$ is the Frequency, $G_{T x}$ is the gain of the transmitting antenna, $G_{R x}$ is the gain of the receiving antenna and $\mathrm{c}$ is the speed of light in vacuum.

Using equation (1), the implementation of the proposed framework has a high tendency to minimize the FSPL between the transmission antenna (Tx) and the receiving antenna. If $\mathrm{G}_{\mathrm{Tx}}$ and $\mathrm{G}_{\mathrm{Rx}}$ of the two antennae increase with the antenna frequency of $2.4 \mathrm{GHz}$ then the aim of this study is achieved because the gain of the antennas offsets the loss by a certain decibel value as shown in figure 10 .

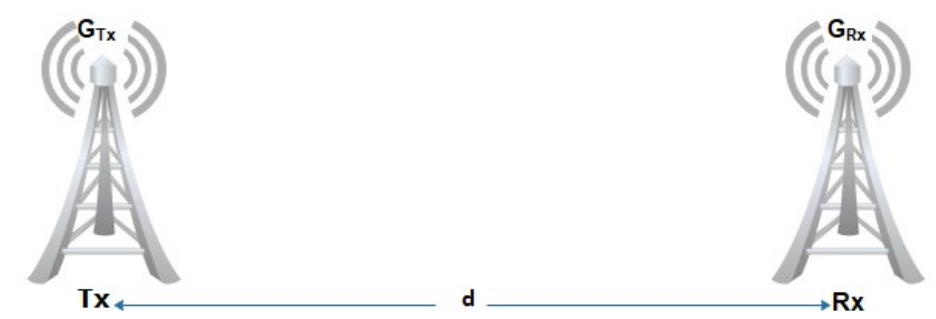

Figure 8: Distance between the transmitting and receiving antennae.

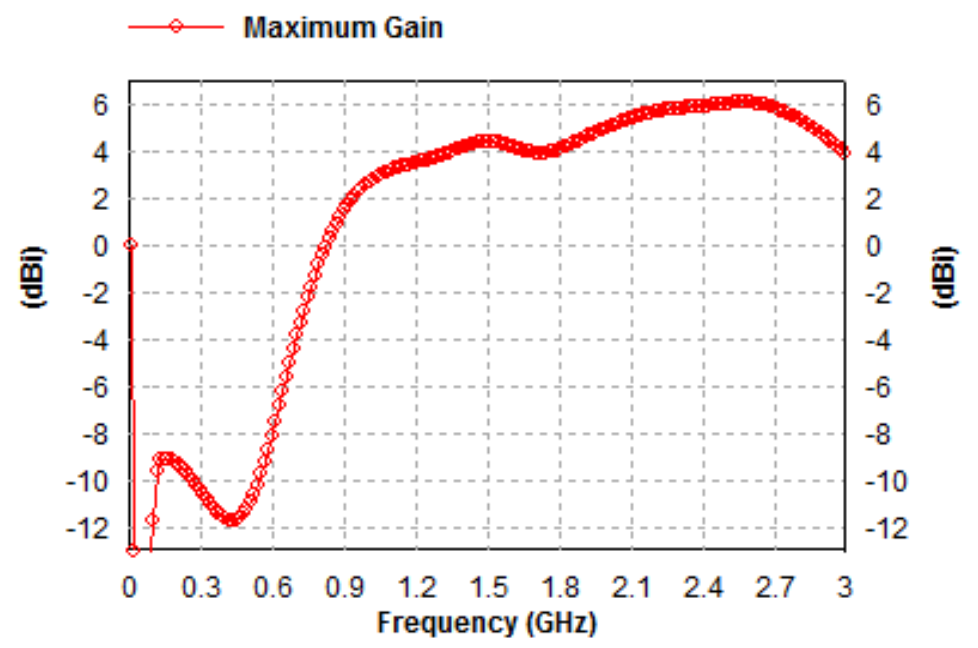

Figure 9: frequency against antenna gain

\section{CONCLUSION}

The study sought to examine the availability and accessibility of internet service on the campuses of the selected universities, evaluate the benefit of campus internet service utilization by students. The situation on campuses of these three universities concerning internet service accessibility has been extremely poor. The test conducted indicates the wireless signal does not actually reach the intended users. Users mostly find it difficult to connect to 
the internet in the offices and various open spaces. The proposed framework provides a perfect solution to these problems. The improved $802.11 \mathrm{a} / \mathrm{b} / \mathrm{g} / \mathrm{n}$ WAP campus infrastructure as presented in this paper has a greater tendency to improve accessibility and high data throughput when implementing in a real-world situation. The universities could adopt the proposed infrastructure to enhance its campus internet connectivity.

\section{SOURCES OF FUNDING}

This research received no specific grant from any funding agency in the public, commercial, or not-for-profit sectors.

\section{CONFLICT OF INTEREST}

The author have declared that no competing interests exist.

\section{ACKNOWLEDGMENT}

None.

\section{REFERENCES}

[1] Harald Haas, Cheng Chen, Dominic O’Brien (2017) A guide to wireless networking by light, Progress in Quantum Electronics, Volume 55, 2017, Pages 88-111, ISSN 0079-6727, https://doi.org/10.1016/j.pquantelec.2017.06.003.

[2] Nyarko-Boateng, O., Xedagbui, F. E. B., Adekoya, A. F., \& Weyori, B. A. (2020). Fiber optic deployment challenges and their management in a developing country: A tutorial and case study in Ghana. Engineering Reports, 2(2), e12121.

[3] Odero, D. J., \& Mutula, S. M. (2007). Internet Access in Kenyan University Libraries. Malaysian Journal of Library \& Information Science, 12(1), 65-81.

[4] Owusu Nyarko-Boateng, Adebayo F. Adekoya and Benjamin A. Weyori (2019). Investigating QoS and Performance of Received Signal Strength Indicator in Fiber Optics Broadband Data Communication. AJEAS. DOI: 10.3844/ajeassp.2019.391.401; Volume 12, Issue 3. Pages 391-401

[5] Penard, T., Poussing, N., Mukoko, B., Bertrand, G., \& Piaptie, T. (2015). Technology in Society Internet adoption and usage patterns in Africa: Evidence from Cameroon. Technology in Society, 42(2015), 71-80. https://doi.org/10.1016/j.techsoc.2015.03.004

[6] Pontes, H. M., Szabo, A., \& Griffiths, M. D. (2015). The impact of Internet-based specific activities on the perceptions of Internet addiction, quality of life, and excessive usage: A cross-sectional study. Addictive Behaviors Reports, 1, 19-25. https://doi.org/10.1016/j.abrep.2015.03.002

[7] Nyarko-Boateng, O., \& Adekoya, A. F. (2019). Evaluation and analysis of key performance indicators which affect the QoS of mobile call traffic. International Journal of Computer Networks (IJCN), 9 (1), 14-30

[8] Ying Qu, Bryan Ng, Michael Homer (2017). A goodput distribution model for planning IEEE 802.11 WBNs in built environments, Journal of Network and Computer Applications, Volume 99, 2017, Pages 28-46, ISSN 1084-8045, https://doi.org/10.1016/j.jnca.2017.10.005.

[9] Kadir, E. A., Siswanto, A., \& Syukur, A. (2016, May). Performance analysis of wireless LAN $802.11 \mathrm{n}$ standard for e-Learning. In 2016 4th International Conference on Information and Communication Technology (ICoICT) (pp. 1-6). IEEE.

[10] Abd Ghafar, A., Kassim, M., Ya'acob, N., Mohamad, R., \& Ab Rahman, R. (2020). QoS of Wi-Fi performance based on signal strength and channel for indoor campus network. Bulletin of Electrical Engineering and Informatics, 9(5), 2097-2108.

[11] Mohamed, M. A. A. (2019). Development of Efficient Technologies for Multimedia Streaming over Wireless Networks (Doctoral dissertation, Mansoura University). 